\title{
Review
}

\section{What is the effect of age on wound healing in the acute trauma setting? A scoping review}

\section{Upton L}

Keywords trauma, wounds, elderly, nursing, clinical practice

For referencing Upton L. What is the effect of age on wound healing in the acute trauma setting? A scoping review. Wound Practice and Research 2020; 28(3):115-126.

DOI https://doi.org/10.33235/wpr.28.3.115-126

\section{Abstract}

The ability to heal an acute traumatic wound or wounds is a complex matrix of overlapping biological processes impacted by intrinsic and extrinsic human factors. As we age, the body's physiological resilience is compromised and homeostasis becomes difficult to maintain. This scoping review examines the influence of biological ageing and the impact of age-related concerns on wound healing, including frailty, malnutrition, pre-existing medical conditions and clinician practices. Frailty rather than age was seen to have a greater physiological impact on outcome, resilience and healing. Clinician support, education and engagement were fundamental to achieve acute wound healing in the aged population. With an increasing ageing population, specialised knowledge, guidelines and structures to support geriatric care are recommended for best clinical practice.

\section{Introduction}

As we age, the body's physiological resilience is compromised and homeostasis becomes increasingly difficult to maintain ${ }^{1}$. Immunesenescence describes the remodelling of the immune system that is associated with ageing and can be of determent for health outcomes ${ }^{1}$. This involves the

\section{Larelle Upton}

Diploma Applied Science (Nursing)

Bachelor of Nursing

Masters of Nursing (Wound Management)

Clinical Nurse Specialist - Trauma and

Orthopaedic, Alfred Health

Clinical Nurse Specialist - Nurse Lead, Vascular

Wound Clinic, Alfred Health

Affiliations: Alfred Health and LaTrobe University Email l.upton@alfred.org.au composition, characteristics and function of cells and systematic inflammation responses ${ }^{1}$.

Age is often regarded as the major factor in post-trauma mortality for the geriatric patient ${ }^{2-5}$. Studies which focused on frailty over age, as a predictor for poor outcomes, appear to have greater relevance for clinical interpretation of goals of care ${ }^{6-9}$. The manifestation of frailty is becoming a standardised question when predicting trauma outcomes and futility of aggressive resuscitation and care ${ }^{7-9}$. Internationally, the definition for geriatric is $\geq 65$ years $^{10}$.

Normal wound healing is largely dependent on four factors - infective load on the wound, virulence of bacteria, the environment the wound is in, and the patient's physiological reserve $^{11}$. Predicting normal wound healing relies on the clinician's ability to understand the causes of prolonged healing and failure to heal ${ }^{12,13}$.

\section{Justification for the review}

This review was conducted to establish best practice in caring for the geriatric trauma patient presenting with acute wounds to the acute hospital setting.

The geriatric population are over-represented in poor health outcomes relating to mortality, morbidity and length of stay compared to the younger trauma patient. In Australia, $15 \%$ of the population are aged over 65 years, yet they made up $41 \%$ of all hospitalisation stays in 2016-2017 ${ }^{10}$. Delayed time to wound healing or inability to heal contributes to this burden. Burden does not only come as a strain and cost on the health system, but also increases the burden on the patient's ability to achieve a high quality of life while ageing 1,3,7-9,14.

Internationally, traumatic injuries are increasing and represent the biggest growth in the geriatric population ${ }^{14}$. In a Cochrane review by Ellis et al., there was a consensus for specialised geriatric hospital care through highlighting the immediate and 
increased need in the geriatric patient population ${ }^{15}$. In Australia, the Victorian trauma model provides this specialised care in the established trauma system ${ }^{16}$. Acknowledgement of the intrinsic and extrinsic factors that predispose the individual's ability to heal need to be comprehensively understood by the clinician. Developing a management plan is also essential to address the underlying factors that delay or reduce the ability to heal ${ }^{13}$. By providing strategies, education and reference points, it is anticipated this vulnerable population can receive preventative and/or early involvement, rather than intervention when complication occurs. Normal barriers to healing are intensified in the older patient population due to tissue health, frailty, malnutrition, susceptibility to greater harm and comorbidities ${ }^{15}$.

\section{Method}

A scoping literature review was undertaken to examine the question - What is the effect of age on wound healing in the acute trauma wound setting? Compared to the younger adult population, the intention is to identify the physiological differences in geriatric skin, vulnerability to complications, and responses to nursing treatments as all of these impact time to heal and whether complete healing can be achieved. The PICO format was developed to assist clinicians determine these outcomes (Table 1).

\section{Search strategies}

Online databases - including MEDLINE, Cochrane, ClinicalKey, CINAHL, ProQuest, Embase, Joanna Briggs Institute (JBI), ScienceDirect - were systematically searched using keywords in OVID (Table 2).

\section{Eligibility criteria}

Inclusion and exclusion criteria were developed (Table 2). There were many articles found which related to the keywords from 1998-2010. The focus of these was related to the influx of dressing products and devices on the market at the time; however, articles that focused on dressings or wound products were excluded due to irrelevance to the current review.

\section{Study selection}

The results of the online data search were imported into reference manager EndNote.

\section{Critical appraisal}

Full text articles were appraised using the Joanna Briggs Institute (JBI) levels of effectiveness and meaningfulness ${ }^{17}$.

\section{Results}

A total of 56 articles were identified for inclusion using the search strategies. A scoping review was conducted according to the preferred reporting items for systematic reviews and meta-analysis (PRISMA) statement (Figure 1) $)^{18,19}$. Extracted themes examine the influence of biological ageing and the impact of age-related concerns on wound healing, including frailty, malnutrition, pre-existing medical conditions and clinician practices (Table 3 ).

\section{Discussion}

Sen et al. introduced the notion of "wound science as an interdisciplinary field" to combat the enormous social and economic impact of wounds and wound healing ${ }^{58(p .763)}$. They postulate categorising wounds as a separate diagnosis and to be viewed as a specialty rather than grouping under the connected illness such as diabetes for diabetic foot ulcers. They reported an overshadowing and under-financing of wound importance through the current approach. Dyer and Miller supported this notion with the older population, adopting the term dermatoporosis to convey skin fragility in ageing and wanting this to be viewed as a "unique clinical syndrome" 41 (p.13). They noted key features of dermatoporosis to include, "atrophic skin with purpura and white pseudoscars on the extremities of elderly patients... and delayed healing" as common presentations ${ }^{41(p .13)}$.

Trauma in the older person occurs with falls, motor vehicle accidents, recreational incidents, accidents, assaults and self-inflicted harm. Acute traumatic wounds occur from external and internal forces directly related to the mechanism of injury. External injury forces include lacerations, abrasions, penetrations, deglovings, amputations and burns. Internal

Table 1. PICO format

\begin{tabular}{|l|l|}
\hline P = Patient or population & $\begin{array}{l}\text { PICO } \\
\text { - Geriatric/older trauma patient }\end{array}$ \\
\hline I = Intervention & $\begin{array}{l}\text { - Nursing assessment of acute trauma wounds } \\
\text { - Nursing identification of wound healing in acute trauma wounds }\end{array}$ \\
\hline C = Comparison & \begin{tabular}{l} 
- Younger adult trauma patient population \\
\hline O = Outcome
\end{tabular} \\
\hline
\end{tabular}


forces causing wounds include orthopaedic and blunt trauma injuries. Blunt forces resulting in morel-lavallee lesions, ecchymosis or compartment syndrome can cause skin necrosis and delayed wound presentation. The main mechanism of injury of the older trauma patient is falling from a low height; this is closely followed by motor vehicle accidents $^{27}$. Wounds sustained from these mechanisms are extensive and range from large, open, degloving wounds to simple abrasions. Complex surgical wounds are common with traumatic injury mechanisms and add to the wound complexity of the patient.

Wound healing is a multifaceted matrix of overlapping processes, from inflammation through proliferation to maturation. When re-epithelialisation has successfully been accomplished, a wound can be classified as healed. Epidermal changes occurring with normal ageing result in a flattening of the dermal-epidermal junction, reduced keratinocyte proliferation, and an extended turnover time ${ }^{61}$. An imbalance in collagen production and degradation reduces dermal vascularity. Skin is more vulnerable to further injury, due to decreased elastin, increased epidermal atrophy, and reductions in nerve ending ${ }^{57}$. Sgonc and Gruber's review observed that wound healing was delayed with normal ageing rather than it being defective ${ }^{60}$. These delays occur in each stage of wound healing, with the flowon effect impacting on the next phase. This emphasises the importance of providing the best environment for wound healing to occur, acknowledging that it may take greater time. Understanding wound healing mechanisms assists in the TIME (tissue debridement, infection or inflammation, moisture balance and edge effect) principle being utilised by clinicians in their wound care ${ }^{35}$. The goals of care are to improve outcomes on the acute wound, thereby maximising health status and prevention of complication.

\section{Impacts of age-related concerns on wound healing}

There are many different impacts of age-related concerns on wound healing in the acute trauma setting, including frailty, malnutrition, pre-existing medical conditions and clinician practices. Some of these will be discussed below.

\section{Inflammation / coagulopathy}

Platelet activation and aggregation results in clot formation during haemostasis and is a key component of the attraction of inflammatory cells to the wound site ${ }^{56}$. Patients taking anticoagulant and or antiplatelet medication have a delay in the initial clotting cascade and an increase in active bleeding. While impacting on this initial stage of healing, blood loss from wounds and injuries can quickly result in life-threatening hypovolemia and shock.

The Trauma Victoria guideline dictates early identification and monitoring of haemoglobin and clotting profiles with treatment to be immediately ${ }^{64}$. Physiologically, acute inflammatory responses can be delayed due to alterations

Table 2. Methodology, keywords and inclusion and exclusion criteria

\begin{tabular}{l|l} 
Online databases & Keywords
\end{tabular}

- MEDLINE

- Cochrane

- ClinicalKey

- CINAHL

- Proquest

- Embase

- Joanna Briggs Institute (JBI)

- ScienceDirect

- Intranet hospital setting

- Prompt, policy and guideline portal

- Government health department

Inclusion criteria

- Adult participant (>18yrs)

- English language

- Studies which involved human participants

- Studies from 1998-2019

- Original research articles

- Studies which examined biological ageing and impact on wound healing, include frailty, malnutrition, pre-existing medical condition and clinician practices
- Aged, geriatric, elderly, older, adult

- Frailty

- Nursing, nursing care

- Wound: wound, acute, traumatic, trauma, care, management, assessment, identification, principles, complications

- Skin, epithelisation

- Healing, acute phases, acute

- Non-healing

- Trauma, injury forces

- Complications, impact, response

- Physiological

Exclusion criteria

- Abstract only articles

- Conference presentations

- Studies which examined wound dressings or wound products 
Figure 1. PRISMA flow chart
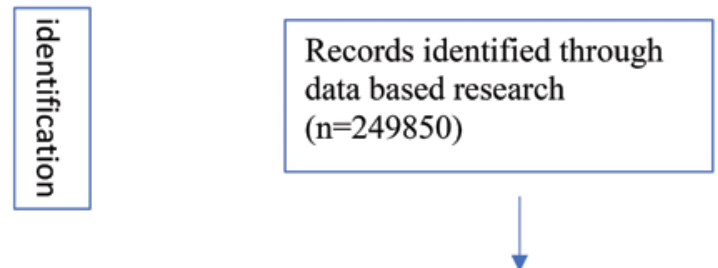

\section{Additional records identified} through other sources $(n=5)$

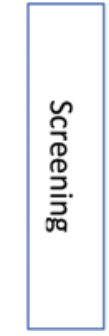
Records after duplicates removed $(n=980)$
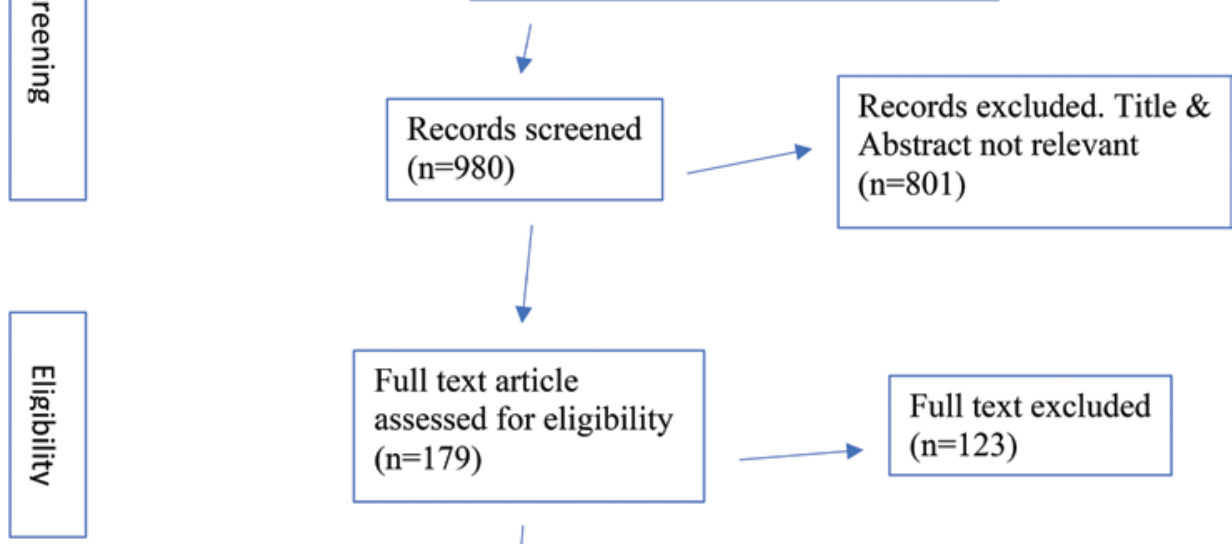
Full text article assessed for eligibility $(\mathrm{n}=179)$
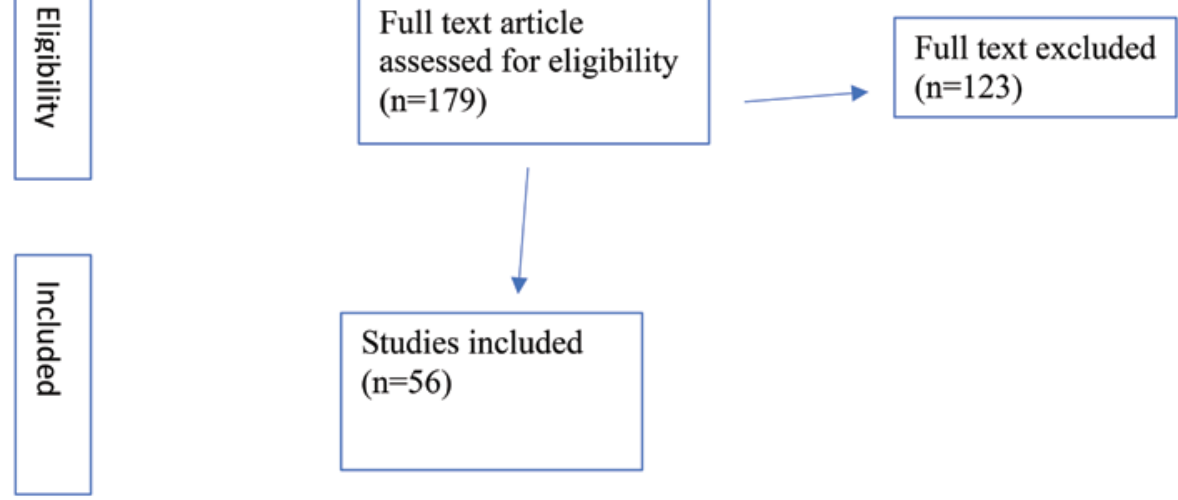

in cytokine production, cell adhesion and migrations; these all occur with ageing ${ }^{23}$. A common feature of delayed healing is an extended inflammatory stage ${ }^{35}$. Mimicking this at a system level, Hazeldine et al.'s systematic review found this same detrimental, sustained inflammatory response in the geriatric trauma patient population ${ }^{1}$. It exposed an abnormal response culminated in extended inflammation, decreased immune responses, and resultant delays or failure to return to homeostasis. In addition, Soysal et al.'s systematic review and meta-analysis concluded a direct relationship between higher serum inflammatory levels and frailty ${ }^{9}$. A relationship appears to occur between inflammation and frailty, with increased mortality, morbidity and hospital length of stay outcomes.

\section{Proliferation}

Granulation tissue formation is reliant on angiogenesis to be initiated and sustained with an adequate blood supply ${ }^{35}$. With ageing, a reduction in the capability for angiogenesis and delayed re-vascularisation result in prolonged healing. Greenhalgh described the skin changes prevalent with ageing - including impairment of new vessels and their perplexity to leak, delayed lymphatic draining and oedema - as major causes of stalled wound healing ${ }^{46}$. In normal healing, the vascular disruption, causing hypoxia, stimulates hypoxia inducible factor and stromal-derived factor, which in turn promotes keratinocyte and fibroblast migration, induce angiogenesis, and stimulating healing ${ }^{60}$. In the aged, this hypoxic reaction appears impaired, therefore impacting on blood vessel formation, and oxygen and nutrient transport to the wound.

\section{Tissue remodelling}

The final phase of wound healing is tissue remodelling. During this stage, extracellular matrix inside the granulation tissue matures and increases in strength, resulting in a collagen-rich scar $^{65}$. In the tissue remodelling stage, age appears to impact collagen remodelling and deposits. A diminished blood supply reduces the extracellular matrix and delays tissue approximation. Wounds healed under suboptimal conditions appear to have greater susceptibility to secondary insult of infection and repeated trauma ${ }^{60}$. Bond et al.'s observational study, using healthy volunteer, found shorter maturation time and better scar quality in the older adults when in an optimal 
environment ${ }^{26}$. Sgonc and Gruber hypothesised, "while ageing adversely effects the speed of wound healing during early phases, it may accelerate maturation and improve scar quality under optimal wound care"60(p.163). These studies rely heavily on optimal wound environments and the 'healthy' older patient, identifying that wound healing can occur in this patient population when optimal conditions are achieved.

\section{Healing}

The health of the microcirculation that supplies the wound bed is the determinant factor for wound healing ${ }^{24}$. Noblet et al.'s cohort study, on soft tissue trauma in the aged, could show comparable healing (to younger patients) when identification and optimisation of individual patient challenges are carefully managed ${ }^{54}$. Blass et al.'s randomised controlled trial (RCT) found targeting the microcirculation with antioxidant micronutrients and glutamine achieves greater wound healing in a shorter timeframe ${ }^{25}$. DemidovaRice et al. and Greenhalgh note the presence of diabetes as a major contributor to delayed wound healing and failure to heal ${ }^{35,46}$. Better outcomes can be achieved, with greater clinical awareness, of the existence of delayed healing. Physiologically, in the wound of an otherwise healthy individual with optimal wound bed conditions, healing occurs regardless of age. The presence of pre-existing comorbidities, frailty, malnutrition and vascular disease mean that delayed wound healing and failure to heal can occur. Optimising the health of the patient to enable homeostasis and physiological resilience is therefore a constant clinical challenge in this patient population.

\section{Frailty}

A discussion appears in the literature as to whether age alone is a determinant of poor outcomes and delayed healing. Pure statistics report that patients over 65 are at greater risk of mortality and poor outcomes from trauma than younger patients ${ }^{10}$. These studies look at a direct comparison between the young adult and the older adult. Other studies reflect the need to question the frail-aged verses the wellaged $^{1,3,25,35,60}$. Frailty syndrome is broadly considered as decreased physiologic reserve across multiple organ systems leading to an impaired ability to withstand physiological stress. The frail patient is vulnerable to functional decline, deficit accumulation, and biological response delays ${ }^{20}$. The frail patient's immune responses, including prolonged inflammation, is a well-documented finding ${ }^{9,41,31}$.

Ellis et al.'s intervention study identified the geriatric frail patient as requiring multidisciplinary specialised assessment, care planning and intervention ${ }^{15}$. Frail patients are at a higher risk for poor outcomes following even minor injury, including postoperative complications, discharge to aged care nursing facilities rather than rehabilitation units or home, and death. The concept of frailty has gained international support as a useful assessment. Currently the search is on to find a validated frailty assessment tool. The Canadian study of health and ageing clinical frailty scale is gaining recognition as a benchmark tool ${ }^{31}$. Throughout the literature search, 'frailty' was prevalent in most articles reviewed from 2015 to current. The Canadian frailty assessment tool was cited in many of these articles.

\section{Pre-existing medical conditions}

Pre-existing chronic disease, including heart disease, stroke, cancer, diabetes and chronic lung disease, are jointly accountable for $71 \%$ of all mortality globally ${ }^{66}$. Preexisting conditions predispose patients to traumatic incident, compromise compensatory mechanism, and obstruct recovery. In the trauma setting, Hildebrand et al. ${ }^{3}$ found supporting evidence of pre-existing conditions causing worse outcomes to comparable patient's disease free; however, they also found supporting studies to reject pre-existing conditions as a major factor to poor outcomes following trauma. The studies rejecting pre-morbid conditions as a predictor for poor outcome following trauma were mostly single institution and cohort studies. These studies found pre-hospital care and injury severity score to be the greater predictor of mortality in the older trauma patient.

Hashmi et al.'s systematic review and meta-analysis concluded being unable to find consensus with pre-existing medical conditions' direct impact on poor outcome ${ }^{2}$. Discussion focused on the greater impact of pre-hospital care, the presence of ongoing hypotension, and injury severity score as independent risk factors to poor outcome in the older trauma patient. Hashmi et al. ${ }^{2}$ critiqued these studies that found against pre-morbid conditions as inadequate to correctly provide robust finding for this conclusion. One study concluded mechanism of injury as the biggest predictor for outcome; however, did not report mortality rates based on mechanism of injury².

Brown et al.'s systematic review hesitantly supported the notion of pre-morbid condition as producing poorer outcomes ${ }^{4}$. They discussed the lack of literature and inconsistencies in studies to provide a robust argument to support this notion. The findings of the predictability of disability post-trauma by Gabbe, Harrison, Lyons, Edwards and Cameron ${ }^{43}$ established comorbidities, over age, as the better predictor of poor recovery. This study noted the limitation of a reliable comorbidity definition and measurement tool. In their prospective cohort state-wide study, their results indicated pre-existing comorbid clinical conditions as fundamentally dictating recovery, and even survival, following major and even minor trauma ${ }^{43}$.

While the presence of pre-existing medical conditions impacts on health and well-being and are a contributory factor to trauma, there is inconsistency in their independent contribution in poor outcome in the older trauma patient in the literature. A limitation in trauma-based studies is that death and disability constitute a poor outcome and are often the only measures used. Pre-injury function can be difficult to ascertain in order to provide a reliable post-injury comparison in the older population. Post-injury function is 
Table 3. Overview of published studies

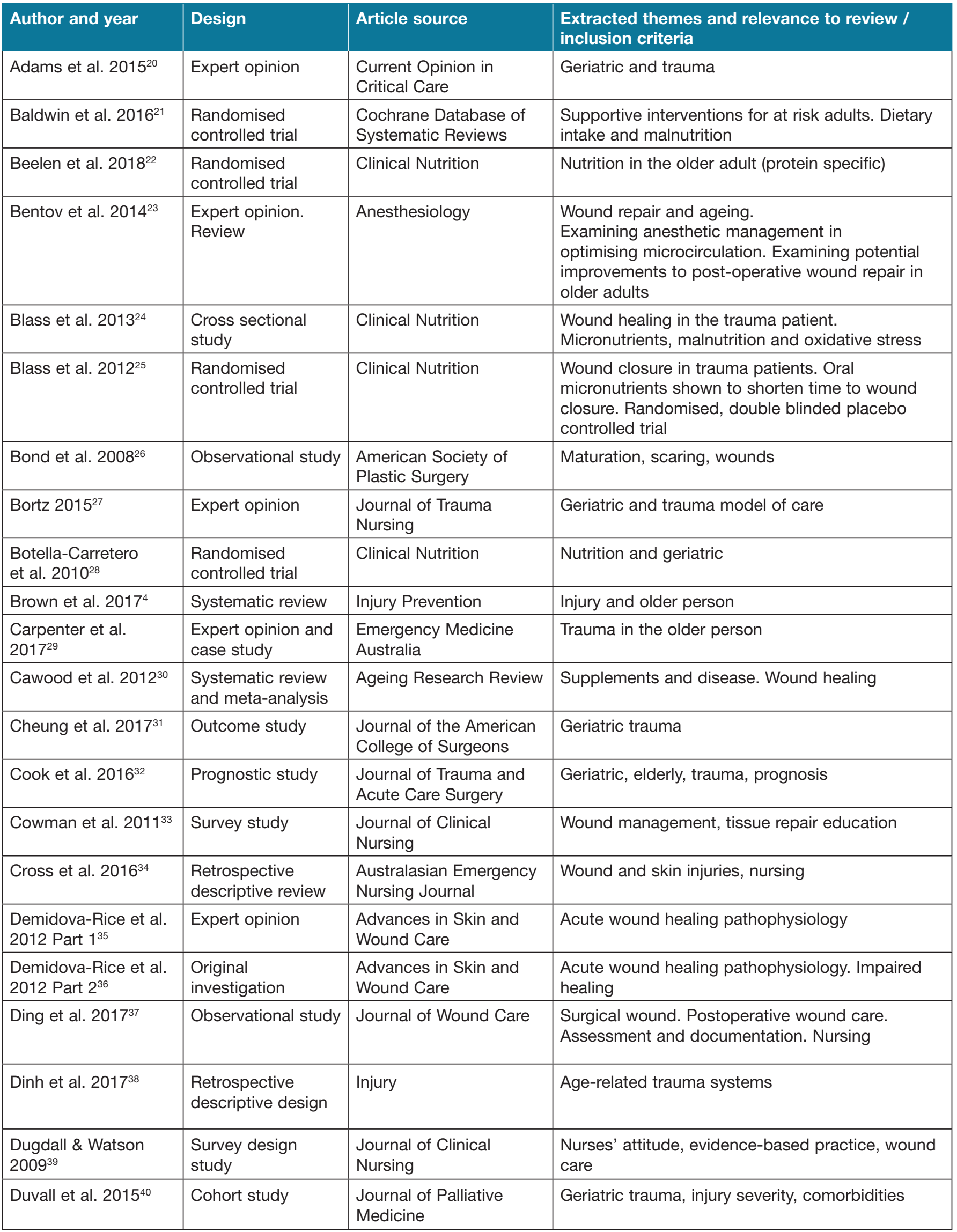


Table 3 continued. Overview of published studies

\begin{tabular}{|c|c|c|c|}
\hline Author and year & Design & Article source & $\begin{array}{l}\text { Extracted themes and relevance to review / } \\
\text { inclusion criteria }\end{array}$ \\
\hline Dyer et al. $2018^{41}$ & $\begin{array}{l}\text { Review of } \\
\text { concepts. Expert } \\
\text { opinion }\end{array}$ & $\begin{array}{l}\text { Journal of Clinical and } \\
\text { Aesthetic Dermatology }\end{array}$ & Skin fragility and ageing \\
\hline Edwards et al. $2017^{42}$ & $\begin{array}{l}\text { Longitudinal pre/ } \\
\text { post }\end{array}$ & $\begin{array}{l}\text { Journal of Clinical } \\
\text { Nursing }\end{array}$ & Prevalence and severity of wounds in the aged \\
\hline Ellis et al. $2017^{15}$ & Systematic review & $\begin{array}{l}\text { Cochrane Database of } \\
\text { Systematic Reviews }\end{array}$ & $\begin{array}{l}\text { Comprehensive geriatric assessment processes } \\
\text { improve outcomes }\end{array}$ \\
\hline Gabbe et al. $2013^{43}$ & Comparison study & $\begin{array}{l}\text { BMC Health Service } \\
\text { Research }\end{array}$ & Aged and trauma outcomes \\
\hline Gillespie et al. $2013^{44}$ & Survey study & $\begin{array}{l}\text { Journal of Clinical } \\
\text { Nursing }\end{array}$ & Wound care. Nursing practices \\
\hline Gitajn et al. $2017^{45}$ & $\begin{array}{l}\text { Retrospective } \\
\text { comparative study }\end{array}$ & $\begin{array}{l}\text { Journal of Orthopaedic } \\
\text { Trauma }\end{array}$ & Geriatric trauma survival \\
\hline Greenhalgh $2015^{46}$ & Expert opinion & $\begin{array}{l}\text { Surgical Clinical North } \\
\text { America }\end{array}$ & Management of skin and soft tissue. Geriatric \\
\hline Fagard et al. $2016^{6}$ & Systematic review & $\begin{array}{l}\text { Journal of Geriatric } \\
\text { Oncology }\end{array}$ & Frailty in the aged \\
\hline Hahnel et al. $2017^{47}$ & Systematic review & $\begin{array}{l}\text { Journal of Tissue } \\
\text { Viability }\end{array}$ & Skin and the aged person \\
\hline Hashmi et al. $2014^{2}$ & $\begin{array}{l}\text { Systematic review } \\
\text { and meta-analysis }\end{array}$ & $\begin{array}{l}\text { Journal of Trauma Acute } \\
\text { Care Surgery }\end{array}$ & Geriatric mortality predictors in trauma \\
\hline Hazeldine et al. $2015^{1}$ & $\begin{array}{l}\text { Review, expert } \\
\text { opinion }\end{array}$ & Ageing Research Review & Geriatric and trauma outcomes \\
\hline $\begin{array}{l}\text { Hilderbrand et al. } \\
2015^{3}\end{array}$ & Review of literature & $\begin{array}{l}\text { Journal of Emergency } \\
\text { Surgery }\end{array}$ & Impact of aged on trauma clinical outcomes \\
\hline Joseph $2015^{48}$ & Expert opinion & Injury & Elderly and trauma burden / opportunity \\
\hline Joseph et al. $2014^{8}$ & $\begin{array}{l}\text { Prospective cohort } \\
\text { study }\end{array}$ & $\begin{array}{l}\text { Journal of the American } \\
\text { Medical Association }\end{array}$ & Frailty, age, trauma, geriatric, predicting outcomes \\
\hline Joyce et al. $2015^{14}$ & Review & $\begin{array}{l}\text { Current Opinion } \\
\text { Anesthesiology }\end{array}$ & Elderly, frailty, geriatric, trauma \\
\hline Koenen et al. $2015^{49}$ & Comparative study & $\begin{array}{l}\text { International Wound } \\
\text { Journal }\end{array}$ & $\begin{array}{l}\text { Acute and chronic wound fluid. Impaired wound } \\
\text { healing }\end{array}$ \\
\hline Li et al. $2017^{50}$ & Systematic review & $\begin{array}{l}\text { International Wound } \\
\text { Journal }\end{array}$ & Wound care \\
\hline Malek et al. $2018^{51}$ & Expert opinion & $\begin{array}{l}\text { Oxidative Medicine and } \\
\text { Cellular Longevity }\end{array}$ & Ageing \\
\hline $\begin{array}{l}\text { McDonald et al. } \\
2016^{7}\end{array}$ & Systematic review & $\begin{array}{l}\text { Journal of Trauma and } \\
\text { Acute Care Surgery }\end{array}$ & Elderly and frailty in trauma \\
\hline Milne et al. $2009^{52}$ & Intervention review & $\begin{array}{l}\text { Cochrane Database of } \\
\text { Systematic Reviews }\end{array}$ & $\begin{array}{l}\text { Protein and energy supplements in elderly at risk } \\
\text { of malnutrition }\end{array}$ \\
\hline Müller et al. $2017^{53}$ & $\begin{array}{l}\text { Cross-sectional } \\
\text { study and } \\
\text { prospective study }\end{array}$ & $\begin{array}{l}\text { European Journal of } \\
\text { Clinical Nutrition }\end{array}$ & Impaired nutrition, geriatric and trauma population \\
\hline
\end{tabular}


Table 3 continued. Overview of published studies

\begin{tabular}{|c|c|c|c|}
\hline Author and year & Design & Article source & $\begin{array}{l}\text { Extracted themes and relevance to review / } \\
\text { inclusion criteria }\end{array}$ \\
\hline Noblet et al. $2018^{54}$ & Cohort study & Injury & $\begin{array}{l}\text { Managing soft tissue in the ageing population. } \\
\text { Limb trauma }\end{array}$ \\
\hline O'Leary et al. $2017^{55}$ & $\begin{array}{l}\text { Retrospective } \\
\text { review }\end{array}$ & $\begin{array}{l}\text { The New Zealand } \\
\text { Medical Journal }\end{array}$ & Older people and trauma \\
\hline Qing $2017^{56}$ & $\begin{array}{l}\text { Expert opinion. } \\
\text { Education } \\
\text { document }\end{array}$ & $\begin{array}{l}\text { Chinese Journal of } \\
\text { Traumatology }\end{array}$ & Wound healing, non-wound healing \\
\hline Reddy et al. $2008^{57}$ & $\begin{array}{l}\text { Expert opinion. } \\
\text { Education } \\
\text { document }\end{array}$ & $\begin{array}{l}\text { Advances in Skin and } \\
\text { Wound Care }\end{array}$ & $\begin{array}{l}\text { Skin and wound repair in the older adult. Normal } \\
\text { verses abnormal changes. Pathophysiology }\end{array}$ \\
\hline Sen et al. $2009^{58}$ & Perspective article & $\begin{array}{l}\text { Wound Repair and } \\
\text { Regeneration }\end{array}$ & Wound. Public health. Ageing population \\
\hline Serra et al. $2017^{59}$ & Systematic review & $\begin{array}{l}\text { International Wound } \\
\text { Journal }\end{array}$ & Skin tear, risk, elderly, nursing \\
\hline Soysal et al. $2016^{9}$ & $\begin{array}{l}\text { Systematic review } \\
\text { and meta-analysis }\end{array}$ & Ageing Research Review & Elderly. Frailty \\
\hline Sgonc et al. $2013^{60}$ & $\begin{array}{l}\text { Mini review. Expert } \\
\text { opinion }\end{array}$ & Gerontology & Wound healing and the aged \\
\hline Ubbink et al. $2015^{13}$ & Prognostic study & $\begin{array}{l}\text { International Wound } \\
\text { Journal }\end{array}$ & $\begin{array}{l}\text { Predicting complex acute wound healing based on } \\
\text { clinical awareness }\end{array}$ \\
\hline Volkert et al. $2018^{61}$ & Guideline & Clinical Nutrition & Nutrition and the elderly \\
\hline Welsh $2017^{62}$ & $\begin{array}{l}\text { Semi-systematic } \\
\text { review }\end{array}$ & $\begin{array}{l}\text { International Wound } \\
\text { Journal }\end{array}$ & Wound care, nursing, education \\
\hline $\begin{array}{l}\text { Wounds Australia } \\
2016^{12}\end{array}$ & Guideline & Wound Australia & Management of wounds \\
\hline $\begin{array}{l}\text { Wuthisuthimethawee } \\
\text { et al. } 2014^{63}\end{array}$ & Expert opinion & World Journal of surgery & Wound management, trauma \\
\hline
\end{tabular}

often determinant by return to work and education status, which is often not relevant in this population ${ }^{4}$.

Focusing on pre-existing medical conditions and wounds, there is evidence that diabetes and vascular disease directly impact wound healing. The epithelialisation process is impaired in all types of chronic wounds with extended proinflammatory characteristics ${ }^{65}$. When an acute traumatic wound fails to heal, in the absence of infection and frailty, premorbid conditions can be a major cause. Vascular disease and diabetes are the main disease processes identified in chronic wounds. Optimising and treating these underlying conditions gives the best chance of wound healing.

Vascular disease is predominantly venous, arterial or mixed presentation, which impacts the macro-circulation and microcirculation of tissue. Insufficient perfusion and hypoxia cause impaired angiogenesis, collagen deposit and epithelisation ${ }^{50}$.
The WHO global report on diabetes details a rise in adults living with diabetes, with estimates of 422 million worldwide ${ }^{67}$. This same report stated mortality from diabetesrelated complications (heart attack, stroke, blindness, kidney failure and lower limb amputation) in 2012 was 1.5 million globally ${ }^{67}$. Systematic oxidative stress is the underlying trigger, impacting on microvascular endothelial cells due to hyperglycaemic-induced damage ${ }^{68}$. Activation of five intracellular pathways being triggered is the major causative factor in microvascular disease, and the resulting tissue damage, in diabetes ${ }^{68}$.

\section{Nutrition and healing}

In the over 65 years age group, malnutrition is common across all healthcare settings and in the community. The mechanism of malnutrition may be physiological, psychological, economical, educational or social. Malnutrition can be attributed to both the cause and the consequence of ill health, and a contributing factor in sarcopenia, osteoporosis, poor 
wound healing and vulnerability to disease $\mathrm{e}^{53}$. There is a direct correlation between falls and the presence of sarcopenia and osteoporosis $^{30}$.

Nutrition and the presence of malnutrition have been the subject of many higher-level studies. Studies which concentrated on geriatric, trauma or wounds were reviewed. These studies concluded the need for all older patients to be assessed for malnutrition and for diligent efforts to ensure adequate nutrition, and were supportive of a high energy, high protein diet for all at-risk patients ${ }^{12,61}$. The causal relationship to nutrition and healing continues to be a growing analysis / area of study. Blass et al.'s RCT found improved time to heal when antioxidant micronutrients and glutamine supplements were dispensed in disorders of wound healing in trauma patients ${ }^{25}$. They hypothesised delayed healing was due to oxidative burden, increased cell requirements and elevated inflammation, which reduced albumin levels needed to facilitate the micronutrient transport to the wound. This study was adult traumatic wound-specific, with age not a consideration. Of the patients randomly selected to the placebo, $67 \%$ were in the 65 years and above category.

Muller et al. ${ }^{53}$ studied the malnutrition of older trauma patients at time of injury, and concluded there was a two-fold greater odds of a poorer outcome when malnourished compared to the patients who were well nourished at the time of the injury. They also found a correlation between frailty and malnutrition. Botella-Carretero et al.'s RCT introduced oral nutritional supplements prior to hip fracture surgery in the older population ${ }^{28}$. The results showed the intervention group had less complications post-operation, hypothesising the reason for this was the increase in serum protein. There was inconclusive evidence for reduced mortality and decreased length of stay in this study. Cawood et al.'s systematic review and meta-analysis supported Botella-Carretero et al.'s finding of reduction in complications with high protein oral supplements ${ }^{30,28}$. This study looked at hospitalised older patients, with a subgroup of nutritional impact on healing. They postulated the positive impact of proteins on inflammatory and immune function. While the focus was on skin tears, Serra, lelapi, Barbetta and de Franciscis identified abnormal albumin levels related to nutrition deficits was on independent risk factor to skin integrity breakdown ${ }^{59}$. Volkert et al.'s guideline on clinical nutrition and hydration in geriatrics supported the implementation of nutritional screening and oral nutritional supplements for all older patients due to the benefits to clinical resilience and quality of life ${ }^{61}$. This focused on sarcopenia and its association with impaired metabolic adaptation to stress and disease, and its direct relation to frailty.

The Cochrane review by Milne, Potter, Vivanti and Avenell ${ }^{52}$ supported the findings of reduction of complications in this surgical population with oral nutritional supplements. The research they reviewed was unable to find an association with supplements reducing mortality, decreased length of stay, nor improving quality of life. They were critical of the gaps in adequate screening of patients and different meanings of definition related to nutritional status. It was concluded, "Most individual's studies in this review had an intervention time that was too short to have a realistic chance of detecting differences in morbidity, functional status or quality of life" $52($ p.16).

\section{Infection and healing}

Traumatic wounds have a high risk of infection due to the nature of the 'dirty' mechanism of injury. Suboptimal wound management, especially early in the patient's trauma journey, results in more extensive infection, tissue necrosis, extra surgical intervention, and more complex closure options ${ }^{63}$. In the traumatic wound, elevated rates of infection follow contamination, tissue loss, inadequate cleaning and debridement, and early wound closure ${ }^{63}$. The wound environment and patient factors generate the greatest risk of infection. Contamination is through microorganism on the patient, environmental contaminants at the time of trauma, and from cross-contamination through clinician wound technique ${ }^{69}$.

The WHO wound management statement recommends recognising the standard classification of trauma wounds as contaminated ${ }^{70}$. They recommend delaying closure of traumatic wounds to ensure adequate debridement of foreign or infected material. Delayed primary closure should be the first option if approximation of wound edges makes this a viable option. Representing a global burden on health, the most common adverse event affecting patient safety are hospital acquired infections ${ }^{71}$. Traumatic and surgical site infection are a serious and costly complication for the trauma patient and the health organisation. As well as causing increased pain and suffering, they increase the risk of mortality, morbidity and hospital length of stay. To achieve a standardised best practice approach, effective infection prevention and control measures need to be established with each clinician interaction ${ }^{72}$. Sepsis also remain a common cause of trauma mortality. Patients have a higher susceptibility to infection with traumatic wounds, malnutrition, pre-existing conditions and frailty ${ }^{73}$.

\section{Clinician education}

Clinician knowledge is paramount in wound healing to achieve successful outcomes. Welsh's semi-systematic review aimed to define the level of evidence supporting nursing wound care decision-making and practice ${ }^{62}$. Welsh established that evidence was limited in wound care practice, and nurses were found to rely on informal sources of knowledge to structure wound care. Further to this, Welsh found ritualistic cultures and inadequate wound care educations at all levels of practice ${ }^{62}$.

The descriptive cross-sectional survey design study by Gillespie, Chaboyer, Allen, Morely and Nieuwenhoven ${ }^{44}$ found nurses surveyed had an appropriate knowledge 
of wound healing; however, evidence-based practices (EBP) were lacking in their wound care. In this convenient sample study, $59 \%$ of nurses were unaware of the national standards for wound care, and over $70 \%$ reported not using practice standards in their wound care. The cross-centre survey design study by Dugdall and Watson ${ }^{39}$ found nurses with higher academic qualifications demonstrated higher clinical knowledge and usage of EBP wound care. Edwards et al.'s pre/post-design study ${ }^{42}$ demonstrated the significant decrease in preventative wound occurrence, improvement skin integrity and increased EBP wound management with wound champions. Ding, Lin, Marshall and Gillespie's crosssectional observational study looked at wound practice alignment to EBP guidelines, and found practices did not consistently align to guidelines ${ }^{37}$. The international eDelphi study, by Cowman et al. ${ }^{33}$, disclosed improved clinician education as number five of the top ten wound priorities from the international respondents. A significant issue discovered in this study was the need for a better understanding of wound bed assessment, wound dressing function, and selection.

\section{Conclusion}

The raw statistics in the trauma population overwhelmingly dictate age as an independent factor of poor outcome. Using the research to improve practices and outcomes requires looking at more specific factors within the older population. In this scoping review, frailty, malnutrition, preexisting comorbidities and clinician education have been appraised regarding their impact on healing and outcomes. Infection has been acknowledged as having an impact on healing and outcome. Controlling and optimising pre-existing medical conditions is vital in the trauma population to assist in the resilience required to maintain homeostasis. Trauma wounds are compromised by pre-existing comorbidities, most notably by vascular disease and diabetes. With the impacts of malnutrition enhancing frailty, falls and fragility to comorbidities, improving and optimising nutrition is essential for good outcomes following trauma. The importance of nutrition in wound healing, infection prevention and decreased susceptibility to infection and sepsis has also been recognised in the literature.

As established by the international guidelines and position statements, clinician skill and knowledge is essential for preventing harm and promoting healing and recovery. Disseminating the knowledge and skill to ensure best practice is a continual and challenging issue in the busy clinical environment. Rituals and unsupported practices need to be replaced by those engaging, educating and guiding clinicians in best practice and wound knowledge and skill.

It has been established that the burden to the health system, the individual and the community when a person sustains a traumatic injury is significant. The older patient population are over-represented in poor health outcomes relating to mortality, morbidity, length of stay and delayed wound healing compared to the younger trauma patient. The findings of searched articles and studies that discuss the impact of age on healing in the acute trauma setting have been presented.

This scoping review has exposed some points for consideration and discussion to improve clinical practice in this vulnerable patient population. The emerging consensus favours the impact of frailty rather than age as having a greater physiological impact on the outcome, resilience and healing. The frail patient is more susceptible to comorbidities, malnutrition and poor outcomes. Clinician support, education and engagement is required to improve the management of pre-existent comorbidities, optimise nutrition, prevent infection, utilise best practice standards in care, and have a complex understanding of wounds and healing. With an increasing ageing population globally, specialised knowledge, guidelines and structures to support geriatric care are paramount.

\section{Conflict of interest}

The author declares no conflict of interest.

\section{Funding}

The author received no funding for this review.

\section{References}

1. Hazeldine J, Lord JM, Hampson P. Immunesenescence and inflammaging: a contributory factor in the poor outcome of the geriatric trauma patient. Ageing Res Rev 2015 Nov 1;24:349-57. doi:10.1016/j.arr.2015.10.003

2. Hashmi A, Ibrahim-Zada I, Rhee P, Aziz H, Fain MJ, Friese RS, Joseph B. Predictors of mortality in geriatric trauma patients: a systematic review and meta-analysis. J Trauma Acute Care Surg 2014 Mar 1;76(3):894-901.10.1097/TA.0b013e3182ab0763

3. Hildebrand F, Pape HC, Horst K, Andruszkow H, Kobbe P, Simon TP, Marx G, Schürholz T. Impact of age on the clinical outcomes of major trauma. Eur J Trauma Emerg Surg 2016 Jun 1;42(3):317-32. doi:10.1007/s00068-015-0557-1

4. Brown K, Cameron ID, Keay L, Coxon K, Ivers R. Functioning and health-related quality of life following injury in older people: a systematic review. Injury Prevent 2017 Dec 1;23(6):403-11. doi:10.1136/injuryprev-2016-042192

5. Schuur J, and Cooper Z. Rosen's emergency medicine: concepts and clinical practice. 2018. Ninth edition. Elsevier. Chapter 184.

6. Fagard K, Leonard S, Deschodt M, Devriendt E, Wolthuis A, Prenen $\mathrm{H}$, Flamaing $\mathrm{J}$, Milisen $\mathrm{K}$, Wildiers $\mathrm{H}$, Kenis $\mathrm{C}$. The impact of frailty on postoperative outcomes in individuals aged 65 and over undergoing elective surgery for colorectal cancer: a systematic review. J Geriatric Oncol 2016 Nov 1;7(6):479-91. doi:10.1016/j.jgo.2016.06.001

7. McDonald VS, Thompson KA, Lewis PR, Sise CB, Sise MJ, Shackford SR. Frailty in trauma: a systematic review of the surgical literature for clinical assessment tools. J Trauma Acute Care Surg 2016 May 1;80(5):824-34. doi:10.1097/ TA.0000000000000981

8. Joseph B, Pandit V, Zangbar B, Kulvatunyou N, Hashmi A, Green DJ, O'Keeffe T, Tang A, Vercruysse G, Fain MJ, Friese RS. Superiority of frailty over age in predicting outcomes among geriatric trauma patients: a prospective analysis. JAMA Surg 2014 Aug 1;149(8):766-72. 
9. Soysal P, Stubbs B, Lucato P, Luchini C, Solmi M, Peluso R, Sergi G, Isik AT, Manzato E, Maggi S, Maggio M. Inflammation and frailty in the elderly: a systematic review and meta-analysis. Ageing Res Rev 2016 Nov 1;31:1-8.

10. Australian Government. Australian Institute of Health and Welfare. 2018. Available from https://www.aihw.gov.au/reports/ older-people/older-australia-at-a-glance/contents/summary

11. Mockford K, O'Grady H. Prevention of surgical site infections. Surgery (Oxford) 2017 Sep 1;35(9):495-9.

12. Wounds Australia. 2016. Standards for Wound Prevention and Management. 3rd edition. Cambridge Media: Osborne Park

13. Ubbink DT, Lindeboom R, Eskes AM, Brull $H$, Legemate DA, Vermeulen $\mathrm{H}$. Predicting complex acute wound healing in patients from a wound expertise centre registry: a prognostic study. Int Wound J 2015 Oct;12(5):531-6. doi:10.1111/iwj.12149

14. Joyce MF, Gupta A, Azocar RJ. Acute trauma and multiple injuries in the elderly population. Curr Opin Anesthesiol $2015 \mathrm{Apr}$ 1;28(2):145-50. doi:10.1097/ACO.0000000000000173

15. Ellis G, Gardner M, Tsiachristas A, Langhorne P, Burke O, Harwood RH, Conroy SP, Kircher T, Somme D, Saltvedt I, Wald $\mathrm{H}$. Comprehensive geriatric assessment for older adults admitted to hospital. Cochrane Database Syst Rev 2017(9). doi:10.1002/14651858.CD006211.pub3

16. Victorian state trauma system. 2018. Victorian state government. Available from: https://www2.health.vic.gov.au/hospitals-andhealth-services/patient-care/acutecare/state-trauma-system

17. Joanna Briggs Institute. New JBI levels of evidence. Adelaide: The Joanna Briggs Institute. 2014 Aug.

18. Moher D, Shamseer L, Clarke M, Ghersi D, Liberati A, Petticrew M, Shekelle P, Stewart LA. Preferred reporting items for systematic review and meta-analysis protocols (PRISMA-P) 2015 statement. Systematic Revs 2015 Dec;4(1):1. oi: 10.1016/j.ijsu.2010.02.007

19. Page MJ, Moher D. Evaluations of the uptake and impact of the Preferred Reporting Items for Systematic reviews and MetaAnalyses (PRISMA) Statement and extensions: a scoping review. Systematic Revs 2017 Dec;6(1):263. doi:10.1186/s13643-0170663-8

20. Adams SD, Holcomb JB. Geriatric trauma. Curr Opin Critical Care 2015 Dec 1;21(6):520-6.

21. Baldwin C, Kimber KL, Gibbs M, Weekes CE. Supportive interventions for enhancing dietary intake in malnourished or nutritionally at risk adults. Cochrane Database Syst Rev 2016(12).

22. Beelen J, Vasse E, Janssen N, Janse A, de Roos NM, de Groot LC. Protein-enriched familiar foods and drinks improve protein intake of hospitalized older patients: a randomized controlled trial. Clin Nutr 2018 Aug 1;37(4):1186-92.

23. Bentov I, Reed MJ. Anesthesia, microcirculation and wound repair in aging. Anesthesiol 2014 Mar;120(3):760.

24. Blass SC, Goost H, Burger C, Tolba RH, Stoffel-Wagner B, Stehle P, Ellinger S. Extracellular micronutrient levels and pro-/antioxidant status in trauma patients with wound healing disorders: results of a cross-sectional study. Nutr J 2013 Dec;12(1):157.

25. Blass SC, Goost H, Tolba RH, Stoffel-Wagner B, Kabir K, Burger $\mathrm{C}$, Stehle P, Ellinger S. Time to wound closure in trauma patients with disorders in wound healing is shortened by supplements containing antioxidant micronutrients and glutamine: a PRCT. Clin Nutr 2012 Aug 1;31(4):469-75.

26. Bond JS, Duncan JA, Sattar A, Boanas A, Mason T, O'Kane S, Ferguson MW. Maturation of the human scar: an observational study. Plastic Reconstruct Surg 2008 May 1;121(5):1650-8. doi:10.1097/PRS.0b013e31816a9f6f
27. Bortz KL. Creating a geriatric-focused model of care in trauma with geriatric education. J Trauma Nurs 2015 Nov 1;22(6):301-5. doi:10.1097/ JTN.0000000000000162

28. Botella-Carretero JI, Iglesias B, Balsa JA, Arrieta F, Zamarrón I, Vázquez C. Perioperative oral nutritional supplements in normally or mildly undernourished geriatric patients submitted to surgery for hip fracture: a randomized clinical trial. Clin Nutr 2010 Oct 1;29(5):574-9. doi:10.1016/j.clnu.2010.01.012

29. Carpenter CR, Arendts G, Hullick C, Nagaraj G, Cooper Z, Burkett E. Major trauma in the older patient: evolving trauma care beyond management of bumps and bruises. Emerg Med Australas 2017 April 29;450-455.

30. Cawood AL, Elia M, Stratton RJ. Systematic review and meta-analysis of the effects of high protein oral nutritional supplements. Ageing Res Rev 2012 Apr 1;11(2):278-96. doi:10.1016/j.arr.2011.12.008

31. Cheung A, Haas B, Ringer TJ, McFarlan A, Wong CL. Canadian Study of Health and Aging Clinical Frailty Scale: does it predict adverse outcomes among geriatric trauma patients? J Am Coll Surg 2017 Nov 1;225(5):658-65.

32. Cook AC, Joseph B, Inaba K, Nakonezny PA, Bruns BR, Kerby JD, Brasel KJ, Wolf SE, Cuschieri J, Paulk ME, Rhodes RL. Multicenter external validation of the Geriatric Trauma Outcome Score: a study by the Prognostic Assessment of Life and Limitations After Trauma in the Elderly (PALLIATE) consortium. J Trauma Acute Care Surg 2016 Feb 1;80(2):204-9.

33. Cowman S, Gethin G, Clarke E, Moore Z, Craig G, Jordan O'Brien J, McLain N, Strapp H. An international eDelphi study identifying the research and education priorities in wound management and tissue repair. J Clin Nurs 2012 Feb;21(3-4):344-53. doi:10.1111/ j.1365-2702.2011.03950.x

34. Cross R, Jennings N, McGuiness W, Miller C. Profiling wound management in the emergency department: a descriptive analysis. Australas Emerg Nurs J 2016 Aug 1;19(3):166-71.

35. Demidova-Rice TN, Hamblin MR, Herman IM. Acute and impaired wound healing: pathophysiology and current methods for drug delivery, part 1: normal and chronic wounds: biology, causes, and approaches to care. Adv Skin Wound Care 2012 Jul;25(7):304

36. Demidova-Rice TN, Hamblin MR, Herman IM. Acute and impaired wound healing: pathophysiology and current methods for drug delivery, part 2: role of growth factors in normal and pathological wound healing: therapeutic potential and methods of delivery. Adv Skin Wound Care 2012 Aug;25(8):349.

37. Ding S, Lin F, Marshall AP, Gillespie BM. Nurses' practice in preventing postoperative wound infections: an observational study. J Wound Care 2017 Jan 2;26(1):28-37. doi:10.12968/ jowc.2017.26.1.28.

38. Dinh MM, Russell SB, Bein KJ, Vallmuur K, Muscatello D, Chalkley D, Ivers R. Age-related trends in injury and injury severity presenting to emergency departments in New South Wales Australia: implications for major injury surveillance and trauma systems. Injury 2017 Jan 1;48(1):171-6.

39. Dugdall $H$, Watson $R$. What is the relationship between nurses' attitude to evidence based practice and the selection of wound care procedures? J Clin Nurs 2009 May;18(10):1442-50.

40. Duvall DB, Zhu X, Elliott AC, Wolf SE, Rhodes RL, Paulk ME, Phelan HA. Injury severity and comorbidities alone do not predict futility of care after geriatric trauma. J Palliative Med 2015 Mar 1;18(3):246-50.

41. Dyer JM, Miller RA. Chronic skin fragility of aging: current concepts in the pathogenesis, recognition, and management of dermatoporosis. Journal Clinical Aesthetic Dermatol 2018 Jan;11(1):13. 
42. Edwards HE, Chang AM, Gibb M, Finlayson KJ, Parker C, O'Reilly M, McDowell J, Shuter P. Reduced prevalence and severity of wounds following implementation of the Champions for Skin Integrity model to facilitate uptake of evidence-based practice in aged care. J Clin Nurs 2017 Dec;26(23-24):4276-85. doi:10.1111/jocn.13752

43. Gabbe BJ, Harrison JE, Lyons RA, Edwards ER, Cameron PA. Comparison of measures of comorbidity for predicting disability 12-months post-injury. BMC Health Serv Res 2013 Dec;13(1):30.

44. Gillespie BM, Chaboyer W, Allen P, Morely N, Nieuwenhoven P. Wound care practices: a survey of acute care nurses. J Clin Nurs 2014 Sep;23(17-18):2618-27. doi:10.1111/jocn.12479

45. Gitajn IL, Castillo R, Breazeale S, Schoonover C, Berger P, Huang Y, O'Hara N, O'Toole RV, Sciadini MF. Survivorship after high-energy geriatric trauma. J Orthopaed Trauma 2017 Aug 1;31(8):e230-5.

46. Greenhalgh DG. Management of the skin and soft tissue in the geriatric surgical patient. Surg Clinic 2015 Feb 1;95(1):103-14. doi:10.1016/j.suc.2014.09.008

47. Hahnel E, Lichterfeld A, Blume-Peytavi U, Kottner J. The epidemiology of skin conditions in the aged: a systematic review. J Tissue Viability 2017 Feb 1;26(1):20-8.

48. Joseph A. Trauma in the elderly: burden or opportunity? Injury 2015;46(9):1701-2.

49. Koenen P, Spanholtz TA, Maegele M, Stürmer E, Brockamp T, Neugebauer E, Thamm OC. Acute and chronic wound fluids inversely influence adipose-derived stem cell function: molecular insights into impaired wound healing. Int Wound $\mathrm{J}$ 2015 Feb;12(1):10-6.

50. Li WW, Carter MJ, Mashiach E, Guthrie SD. Vascular assessment of wound healing: a clinical review. Int Wound J 2017 Jun;14(3):460-9. doi:10.1111/iwj.12622

51. Malek MH, Hüttemann M, Lee I. Mitochondrial structure, function, and dynamics: the common thread across organs, disease, and aging. Oxidative Med Cellular Longevity; 2018.

52. Milne AC, Potter J, Vivanti A, Avenell A. A. Protein and energy supplementation in elderly patients at risk from malnutrition. Cochrane Database Syst Rev 2009(2). doi:10.1002/14651858. CD003288.pub3.

53. Müller FS, Meyer OW, Chocano-Bedoya P, Schietzel S, Gagesch M, Freystaetter G, Neuhaus V, Simmen HP, Langhans W, Bischoff-Ferrari HA. Impaired nutritional status in geriatric trauma patients. Eur J Clin Nutr 2017 May;71(5):602-6. doi:10.1038/ ejcn.2017.25

54. Noblet TM, Jackson PC, Foster P, Taylor DM, Harwood PJ, Wiper JD. Managing soft tissues in severe lower limb trauma in an ageing population. Injury 2018 Jun 1;49(6):1197-202. doi:10.1016/j.injury.2018.03.010

55. O'Leary K, Kool B, Christey G. Characteristics of older adults hospitalised following trauma in the Midland region of New Zealand. NM Med J (Online). 2017 Oct 6;130(1463):45-53.

56. Qing C. The molecular biology in wound healing and nonhealing wound. Chin J Traumatol 2017 Aug 1;20(4):189-93. doi:10.1016/j.cjtee.2017.06.001

57. Reddy M. Skin and wound care: important considerations in the older adult. Adv Skin Wound Care 2008 Sep 1;21(9):424-36.

58. Sen CK, Gordillo GM, Roy S, Kirsner R, Lambert L, Hunt TK, Gottrup F, Gurtner GC, Longaker MT. Human skin wounds: a major and snowballing threat to public health and the economy. Wound Repair Regen 2009 Nov;17(6):763-71.

59. Serra R, lelapi N, Barbetta A, de Franciscis S. Skin tears and risk factors assessment: a systematic review on evidence-based medicine. Int Wound J 2018 Feb;15(1):38-42.
60. Sgonc R, Gruber J. Age-related aspects of cutaneous wound healing: a mini-review. Gerontol 2013;59(2):159-64.

61. Volkert D, Beck AM, Cederholm T, Cruz-Jentoft A, Goisser S, Hooper L, Kiesswetter E, Maggio M, Raynaud-Simon A, Sieber CC, Sobotka L. ESPEN guideline on clinical nutrition and hydration in geriatrics. Clin Nutr 2019 Feb 1;38(1):10-47. doi:10.1016/j.clnu.2018.05.024

62. Welsh L. Wound care evidence, knowledge and education amongst nurses: a semi-systematic literature review. Int Wound J 2018 Feb;15(1):53-61.

63. Wuthisuthimethawee P, Lindquist S, Sandler N, Clavis, O, Korin S, Watters D, Gruen R. Wound management in disaster settings. World J Surg 2014 Apr 39, 842-853. doi:10.1007/s00268-0142663-3

64. Victorian Trauma. Older person trauma; 2018. Available from: http://trauma.reach.vic.gov.au/guidelines/older-person-trauma/ key-messages

65. Krzyszczyk P, Schloss R, Palmer A, Berthiaume F. The role of macrophages in acute and chronic wound healing and interventions to promote pro-wound healing phenotypes. Frontiers Physiol 2018 May 1;9:419.

66. World Health Organization (WHO). Noncommunicable diseases and their risk factors. Available from http://www.who.int/ncds/ en/

67. Roglic G. WHO global report on diabetes: a summary. Int $\mathrm{J}$ Noncommunic Dis 2016 Apr 1;1(1):3.

68. Rafehi H, El-Osta A, Karagiannis TC. Epigenetic mechanisms in the pathogenesis of diabetic foot ulcers. J Diabetes Complicat 2012 Nov 1;26(6):554-61.

69. National Institute for Health and Clinical Excellence (Great Britain). Surgical site infection: prevention and treatment of surgical site infection. National Institute for Health and Clinical Excellence; 2008.

70. World Health Organization (WHO). Wound management. WHO Geneva; 2005. Available from http://apps.who.int/medicinedocs/ documents/s17298e/s17298e.pdf

71. Leaper DJ, Edmiston CE. World Health Organization: global guidelines for the prevention of surgical site infection. J Hosp Infect 2017 Feb 1;95(2):135-6.

72. Farmer T, Mitchell C. Australian infection control guidelines: preventing and managing infection in health care. Healthcare Infect 2010 Dec;15(4):101.

73. Nasa P, Juneja D, Singh O. Severe sepsis and septic shock in the elderly: an overview. World J Crit Care Med 2012 Feb 4;1(1):23. 